\title{
Use of psychotropic medications by caregivers of elderly patients with dementia: is this a sign of caregiver burden?
}

\author{
Uso de psicotrópicos por cuidadores de pacientes idosos com demência: isso é um sinal \\ de sobrecarga do cuidador? \\ Einstein Francisco Camargos ${ }^{1}$, Andrea Brígida Souzaㄹ, Aline Silva Nascimento², Alessandra Cicari Morais- \\ e-Silva², Juliana Lima Quintas³, Luciana Lilian Louzada', Patricia Medeiros-Souza ${ }^{4}$
}

\begin{abstract}
This study evaluated the consumption of psychotropic medications by caregivers of elderly patients with or without dementia. This was a cross-sectional study conducted at all geriatric units in Brasilia, Brazil, during a two-month period. Structured interviews were performed with 311 caregivers of people with or without dementia and they completed questionnaires. Among the caregivers, $196(63 \%)$ were caregivers of patients with dementia and 115 (37\%) were caregivers of patients without dementia. Forty-four caregivers (14.1\%) were taking psychotropic drugs (benzodiazepines or antidepressants), and this usage was more frequent among caregivers of patients with dementia ( $p<0.01$ ). Twenty-two caregivers of patients with dementia (11.4\%) had used sleeping pills after beginning care, compared with only five (4.3\%) caregivers of patients without dementia $(p<0.01)$. In conclusion, this study found that caregivers of patients with dementia took psychotropic drugs (benzodiazepines and antidepressants) more frequently than the ones of patients without dementia.
\end{abstract}

Key words: psychotropic drugs, aged, caregiver, dementia.

\section{RESUMO}

Este estudo avaliou o consumo de drogas psicotrópicas por cuidadores de idosos de pacientes com e sem demência. Este foi um estudo transversal conduzido em todas as unidades de atendimento geriátrico em Brasília, Brasil, durante dois meses. Foram realizadas entrevistas estruturadas e um questionário preenchido por 311 cuidadores de idosos, com e sem demência. Entre os cuidadores, 196 (63\%) eram cuidadores de pacientes com demência e 115 (37\%) de pacientes sem demência. Quarenta e quatro cuidadores (14,1\%) estavam utilizando drogas psicotrópicas (benzodiazepínicos ou antidepressivos). Esse uso foi mais frequente entre os cuidadores de pacientes com demência ( $p<0,01)$. Vinte e dois cuidadores de pacientes com demência $(11,4 \%)$ usaram medicamentos para dormir após iniciar o trabalho de cuidador, comparado com somente 5 (4,3\%) cuidadores de pacientes sem demência ( $p<0,01)$. Em conclusão, este estudo encontrou que cuidadores de pacientes com demência tomavam mais frequentemente drogas psicotrópicas (benzodiazepínicos ou antidepressivos) do que os de pacientes sem demência.

Palavras-Chave: drogas psicotrópicas, idoso, cuidador, demência.

In Brazil, the elderly population approached 21 million in 2009 , and its growth is systematic and steady ${ }^{1}$.

The increase in the elderly population has occurred as a result of social progress, as well as advances in Medicine, which have reduced mortality during the early phases of life ${ }^{1}$. Although progress has been substantial for the treatment of some diseases, it lags behind in the case of neurodegenerative diseases, such as dementias ${ }^{2}$.
Dementia is a chronic disease that is characterized by an irreversible impairment of the cognitive function. The prevalence of dementia worldwide is approximately 24 million with an estimated increase of 4.6 million new cases each year ${ }^{3}$. The current number of people with dementia in Latin America is 1.8 million, and this is predicted to rise to 9.1 million by $2040^{3}$.

In dementia, the loss of functionality initially causes dependence with respect to the instrumental activities of daily living,

${ }^{1}$ Assistent Geriatrician, Geriatric Medical Centre (CMI), University Hospital (HUB), Brasília University (UnB), Brasília DF, Brazil;

2 Pharmacists specializing in Clinical Pharmacy, UnB, Brasília DF, Brazil;

${ }^{3}$ Neuropsychologist, CMI/HUB/UnB, Brasília DF, Brazil;

4 Professor of Pharmacy, Department of Health Sciences, UnB, Brasilia DF, Brazil.

Correspondence: Einstein Francisco Camargos; Department of Medical Clinical, Geriatric Medical Centre, HUB, UnB; SGAN 605; Avenida L2 Norte / Asa Norte; 70840-901 Brasilia DF - Brasil; E-mail: einstein@unb.br

Conflict of interest: There is no conflict of interest to declare.

Received 12 September 2011; Received in final form 27 September 2011; Accepted 04 October 2011 
and this is soon followed by dependence in terms of daily living basic activities, such as feeding, hygiene care, mobility, and so on. The caregiver of an elderly patient, either in a formal situation or a family member, usually assumes active participation with respect to care during the advanced phase of the disease.

A caregiver is defined as a person in the community or a family member that takes care of another people of any age, who need assistance, because they are bedridden, or have physical or mental limitations, with or without remuneration $^{4}$. The main informal caregiver is defined as the person entrusted to assist in the basic and instrumental activities of the patient's daily life during the greater part of the day, without receiving any remuneration ${ }^{5}$.

By that same concept, the task of the caregiver transcends simple assistance with daily activities of the individual, whether they are healthy, sick and/or bedridden, at risk or frail, in their home or in any type of institution in which they need daily care. Caregivers of patients with dementia have unique challenges, for example difficulties with communication and the behavioural disorders that are observed in these patients, such as insomnia, night wandering, agitation, delusions, and others ${ }^{6}$.

The caregiver is usually a member of the family, that is, the wife or the patient's son/daughter, and is frequently female. There is a large number of publications that describe the burden of caregivers of patients with dementia ${ }^{6}$. They have a poor quality of life, and show symptoms of anxiety, depression, insomnia, and stress $^{7,8}$. As a consequence, the caregivers of elderly people with dementia are more susceptible to the use of psychotropic medications than other groups of people of the same age.

Few international studies have addressed this issue. Clipp and George ${ }^{9}$ evaluated 510 caregivers of patients with dementia. The authors observed that one-third of them occasionally used a psychotropic drug, and 19\% used anxiolytic, $4 \%$ antidepressant, and $18 \%$ hypnotic/sedative agents. They used scales for physical and mental evaluation to relate the complaints of the caregivers to the use of psychotropic medication, and found that a lack of social support during care was associated with a 3.7-fold increase in the use of antidepressants.

Given the ageing of the Brazilian population, the resulting increase in the number of individuals with dementia, and the consequent increase in the number of caregivers of people with dementia, aspects related to the health of caregivers should be considered as part of public health policy. The objective of this study was to investigate the use of psychotropic medications by caregivers of elderly patients with (CPD) or without (CPND) dementia in clinics of geriatric medicine in Brasília, Brazil.

\section{METHODS}

\section{Design and setting}

This was a cross-sectional study conducted on CPD and CPND from four centres of geriatric medicine in the Federal District of Brazil (DF) from July to August, 2010. The centres were: Center of Medicine of the Elderly (CMI) of the University Hospital of Brasília, University of Brasília; Geriatrics Clinic of the Regional Hospital of the North Wing (HRAN); Geriatrics Clinic of the Regional Hospital of Guará (HRGu); and the General Clinic of Taguatinga (HRT). These services are responsible for all public services related to elderly people in DF and they are part of the Brazilian Public Health System (SUS). The CMI is accredited by the Brazilian Ministry of Health as a referral centre for patients with Alzheimer's disease in the Brazilian Federal District.

This research was approved by the Ethics Research Committee of the Medical University of Brasília (n. 007/10) and by the Secretary of State for Health (n. 210/10).

\section{Participants}

Definition of caregiver according to the Brazilian Ministry of Health: "family member or person from the community who takes care of another person of any age who needs assistance because they are bedridden, or have physical or mental limitations, with or without remuneration”.

Psychotropic medications act upon the central nervous system (CNS) to produce alterations in behaviour, humour, and cognition; they possess substantial reinforcing properties, and thus are susceptible to self-administration ${ }^{10}$.

The established guidelines for the diagnosis of dementia used by the clinics followed the Diagnostic and Statistical Manual of Mental Disorders (DSM-IV) by the American Association of Psychiatry ${ }^{11}$.

In this study, only the use of benzodiazepines and antidepressants was analysed. The study did not consider the use of antipsychotic, anticonvulsant, or other drugs that act upon the CNS.

\section{Interview}

The caregivers that followed-up an elderly patient in the geriatric consultations, which took place between July, 1 and August, 30, in 2010, were invited to participate in an interview. After the caregivers had signed the informed consent form, they were interviewed by the research pharmacist, and data related to the patient were acquired from medical files. Ten caregivers refused consent. The questions posed to the caregivers were in accordance with the following sequence:

- Have you ever used tranquilizers, sedatives or antidepressants since you began to care for this elderly patient? Yes or no.

- Are you taking such drugs currently? Yes or no.

- No, you are not using such drugs currently, but have you used them before? Yes or no.

The names of any medications used were supplied by the user and classified by the pharmacist as antidepressant, benzodiazepine, and antianxiety.

Health and sociodemographic characteristics were compared between the two groups (response variable): namely, CPND (=0) or CPD (=1). 


\section{Patient variables}

These variables included the location of the medical appointment, age, gender ( female=1); insomnia (present=1), night wandering (present=1), night agitation (present=1), and the use of sleep medication (yes=1).

\section{Caregiver variables}

These included: age; gender (female=1); education, considered in terms of complete years of study and expressed as a dichotomous variable: $>8$ years $=0$ and $<8$ years $=1$; marital status (married, single, separate/divorced, other); other work activity (yes=1); member of the family (yes=1); nature of the family relationship (spouse, son/daughter, other); schedule of caregiving continual, a 12-hour period per day, alternate days, weekends, others); use of any medication (yes=1); use of any prescription-controlled medication (yes $=1$ ); use of benzodiazepines (yes=1); use of antidepressants (yes=1); use of sleeping pills while taking care of the elderly patient (yes $=1$ ); and self-notification of the caregiver's health condition (excellent, very good, good, bad, and very bad).

\section{Statistical analysis}

The statistical analysis was begun by using the Kolmogorov-Smirnov test for normality. Pearson's $\chi^{2}$, the Kruskal-Wallis, and Student's $t$ tests were used to verify the

Table 1. Physical and sociodemographic characteristics of the patients $(n=311)$.

\begin{tabular}{lccc} 
& \multicolumn{2}{c}{ Total (\%) } & \\
Variable & $\begin{array}{c}\text { With } \\
\text { dementia }\end{array}$ & $\begin{array}{c}\text { Without } \\
\text { dementia }\end{array}$ & p-value \\
& $\mathrm{n}=196(63)$ & $\mathrm{n}=115(37)$ & \\
\hline Place of medical care & $100(51.0)$ & $43(37.4)$ & - \\
CMI & $35(17.9)$ & $41(35.7)$ & $<0.001$ \\
HRAN & $46(23.5)$ & $19(16.5)$ & 0.8 \\
HRT Clinic & $15(7.7)$ & $12(10.4)$ & 0.1 \\
HRGu & & & \\
Gender & $63(32.1)$ & $32(27.8)$ & 0.2 \\
Male & $133(67.9)$ & $83(72.2)$ & \\
Female & & & \\
Insomnia & $93(47.4)$ & $39(33.9)$ & 0.02 \\
Yes & $103(52.6)$ & $76(66.1)$ & \\
No & & & \\
Night wandering & $41(20.9)$ & $12(10.4)$ & 0.01 \\
Yes & $155(79.1)$ & $103(89.6)$ & \\
No & & & \\
Night agitation & & & \\
Yes & $67(34.2)$ & $21(18.3)$ & 0.003 \\
No & $129(65.8)$ & $94(81.7)$ & \\
Does he/she use sleep & & & \\
medication? & & & \\
Yes & $117(59.7)$ & $40(34.8)$ & $<0.001$ \\
No & $79(40.3)$ & $75(65.2)$ & \\
\hline
\end{tabular}

"Pearson's correlation; CMI:Center of Medicine of the Elderly;HRAN: Regional Hospital of the North Wing; HRT: General Clinic of Taguatinga; HRGu: Regional Hospital of Guará statistical significance of the differences found among proportions and averages. The analyses were performed using the statistical program SPSS, version 17.0. All of the p-values were two-tailed $(\alpha=0.05)$.

\section{RESULTS}

A total of 311 caregivers of elderly patients were interviewed: 196 (63\%) in the CPD Group and 115 (37\%) in the CPND Group. The mean age of the elderly patients was 77.7 years $( \pm 8.3)$, and there was no difference between the groups with respect to gender. The sociodemographic characteristics and the health status of the patients are given in Table 1.

The mean age among the caregivers overall was 50.7 years-old $( \pm 14.0)$. The CPD Group had a greater mean age than the CNPD Group (51.9 \pm 13.6 versus $48.7 \pm 14.4$ years-old, $\mathrm{p}=0.04$ ). The sociodemographic characteristics of the caregivers and their relationship to the use of medications by the CPD and CNPD Groups are illustrated in Tables 2 and 3, respectively.

Table 2. Physical and sociodemographic characteristics of caregivers of elderly patients with or without dementia $(n=311)$

\begin{tabular}{|c|c|c|c|}
\hline \multirow[b]{2}{*}{ Variable } & \multicolumn{2}{|c|}{ Total (\%) } & \multirow[b]{2}{*}{$p$-value } \\
\hline & $\begin{array}{c}\text { With } \\
\text { dementia } \\
\mathrm{n}=196(63)\end{array}$ & $\begin{array}{c}\text { Without } \\
\text { dementia } \\
n=115 \text { (37) }\end{array}$ & \\
\hline \multicolumn{4}{|l|}{ Gender } \\
\hline Male & $33(16.8)$ & $28(24.3)$ & 0.1 \\
\hline Female & $163(83.2)$ & $87(75.7)$ & \\
\hline \multicolumn{4}{|l|}{ Educational level } \\
\hline$\leq 8$ years & 77 (39.3) & $37(32.2)$ & 0.2 \\
\hline$>8$ years & $119(60.7)$ & $78(67.8)$ & \\
\hline \multicolumn{4}{|l|}{ Marital status } \\
\hline Married & $117(59.7)$ & $67(58.3)$ & $0.8^{\#}$ \\
\hline Single & $50(25.5)$ & $30(26.1)$ & \\
\hline Separated/divorced & $21(10.7)$ & $11(9.6)$ & \\
\hline Other & $8(4.1)$ & $7(6.1)$ & \\
\hline \multicolumn{4}{|c|}{$\begin{array}{l}\text { Does he/she have another work } \\
\text { activity? }\end{array}$} \\
\hline Yes & $72(36.7)$ & $55(47.8)$ & 0.054 \\
\hline No & $124(63.3)$ & $60(52.2)$ & \\
\hline \multicolumn{4}{|c|}{ Is he/she a member of the family? } \\
\hline Yes & $176(89.8)$ & $110(95.7)$ & 0.06 \\
\hline No & $20(10.2)$ & $05(4.3)$ & \\
\hline \multicolumn{4}{|l|}{ Family relationship } \\
\hline Husband/wife & $38(21.6)$ & 19 (17.3) & $0.7^{\#}$ \\
\hline Son/daughter & $126(71.6)$ & $69(62.7)$ & \\
\hline Other & $32(16.3)$ & $27(23.5)$ & \\
\hline \multicolumn{4}{|l|}{ Working shift } \\
\hline Continual & $133(67.9)$ & 70 (60.9) & $0.4^{\#}$ \\
\hline 12-hour period & $22(11.2)$ & $10(8.7)$ & \\
\hline Alternate days & $11(5.6)$ & $11(9.6)$ & \\
\hline Weekends & $10(5.1)$ & $09(7.8)$ & \\
\hline Other & $20(10.2)$ & $15(13.0)$ & \\
\hline
\end{tabular}

*Pearson's correlation;" Kruskal-Wallis test. 
Table 3. Use of medications, psychotropic medications, and health condition of caregivers of elderly patients with or without dementia $(n=311)$.

\begin{tabular}{|c|c|c|c|}
\hline \multirow[b]{2}{*}{ Variable } & \multicolumn{2}{|c|}{ Total (\%) } & \multirow[b]{2}{*}{$p$-value } \\
\hline & $\begin{array}{c}\text { With } \\
\text { dementia } \\
n=196(63)\end{array}$ & $\begin{array}{c}\text { Without } \\
\text { dementia } \\
n=115(37)\end{array}$ & \\
\hline \multicolumn{4}{|l|}{$\begin{array}{l}\text { Does he/she take any } \\
\text { medication? }\end{array}$} \\
\hline Yes & $118(60.2)$ & $56(48.7)$ & 0.04 \\
\hline No & $78(39.8)$ & 59 (51.3) & \\
\hline \multicolumn{4}{|l|}{$\begin{array}{l}\text { Does he/she use any } \\
\text { prescription-controlled } \\
\text { medication? }\end{array}$} \\
\hline Yes & $36(18.4)$ & $08(7.0)$ & 0.005 \\
\hline No & $160(81.6)$ & $107(93.0)$ & \\
\hline \multicolumn{4}{|l|}{$\begin{array}{l}\text { Does he/she take } \\
\text { benzodiazepines? }\end{array}$} \\
\hline Yes & $14(7.3)$ & $01(0.9)$ & 0.01 \\
\hline No & $179(92.7)$ & $114(99.1)$ & \\
\hline \multicolumn{4}{|l|}{$\begin{array}{l}\text { Does he/she take } \\
\text { antidepressants? }\end{array}$} \\
\hline Yes & $22(11.4)$ & $05(4.3)$ & 0.03 \\
\hline No & $171(88.6)$ & $110(95.7)$ & \\
\hline \multicolumn{4}{|l|}{$\begin{array}{l}\text { Did he/she use sleep } \\
\text { medication while taking care } \\
\text { of the elderly patient? }\end{array}$} \\
\hline Yes & $62(31.6)$ & $18(15.7)$ & 0.002 \\
\hline No & $134(68.4)$ & $97(84.3)$ & \\
\hline \multicolumn{4}{|l|}{$\begin{array}{l}\text { How does he/she consider } \\
\text { his/her health condition? }\end{array}$} \\
\hline Good, very good or excellent & $174(88.8)$ & $105(91.3)$ & 0.4 \\
\hline Bad or very bad & $22(11.2)$ & $10(8.8)$ & \\
\hline
\end{tabular}

Forty-four caregivers (14.1\%) used psychotropic medications, and this use was more frequent among the CPD Group than among the CPND one ( $\mathrm{n}=36$ versus $\mathrm{n}=8, \mathrm{p}<0.01)$. Among these 44 caregivers, 15 (4.8\%) used benzodiazepines and 27 (8.6\%), antidepressants.

\section{DISCUSSION}

This study, which took place in centres of geriatric medicine in Brasília, found that the CPD Group used medications, mainly psychotropic drugs, more frequently than the CNPD one.

The patient's sample was representative of the routine medical service in geriatric clinics, and it included patients both with and without dementia. The large proportion of patients with dementia among the group from the CMI was due to the fact this centre is a referral centre for the treatment of such disease in the DF. With regard to the individual characteristics recorded during the study, the presence of sleep disturbance, night wandering and night agitation, and the use of sleeping pills were common in the patients with dementia $^{12}$. Although the diagnosis of sleep disturbance in patients with this condition is based on specific criteria, the information provided by the caregiver should be considered to be basically subjective, in spite of being similar in the two groups of caregivers (CPD and CNPD).

The characteristics of the patient show a direct relationship with the quality of life of the caregiver. Caregivers of dementia patients with sleep disturbance complain more frequently of insomnia than the ones of patients with dementia, whose sleep is not disturbed. In fact, this is an important cause of institutionalization in nursing homes ${ }^{13}$. Night wandering and agitation has an equal impact on the quality of life of the caregiver and patient. Moreover, research has shown that caregivers of patients with dementia have high levels of hormones related to stress and a low antibody response to infection ${ }^{14}$.

Regarding the sample of caregivers, the gender distribution did not differ from that observed in other Brazilian and international studies; the sample being composed basically of women ${ }^{9,15,16}$. In this study, the majority of caregivers was the unemployed sons/daughters of patients who did not have a job but had a high level of education. The involvement of sons/daughters as caregivers and their advanced age (a mean of 48 years-old) have also been observed in other national and international studies ${ }^{7,15,17}$.

Caregivers of elderly patients with dementia have a poor quality of life and are more likely to have insomnia and depression, as well as more severe health conditions ${ }^{7,8,18}$. Their symptoms depend on the severity of the patient's dementia? It was not an objective of the present study to evaluate the presence of insomnia or depression in caregivers.

It was observed that 44 (14\%) of the caregivers used psychotropic medications, the majority being antidepressants. This proportion is higher than the frequency of use of psychotropic medications in the general population, as reported in previous studies. For example, Rodrigues et al. found that, in the city of Pelotas, psychotropic medications were used by $9.9 \%$ of the population ${ }^{19}$.

With regard to the use of psychotropic drugs by caregivers, other studies observed high levels of use, which varied from 24 to 31\% $\%^{9,20-22}$. Study by Clipp and George9, which involved 510 American caregivers of patients with dementia, demonstrated that $30 \%$ used psychotropic medications occasionally. Subsequent studies have identified a high prevalence (31\%) of the use of psychotropic drugs by caregivers of stroke victims ${ }^{20}$. Similarly to the current study, these studies used questionnaires to obtain the required information. Factors that predispose caregivers to the use of psychotropic medication are: female sex, low educational level, frequent medical appointments, high number of stress factors, low life satisfaction, poor health status ${ }^{9,18}$ and a large number of diseases ${ }^{18}$.

A study based on a questionnaire survey of 2,032 American caregivers of patients with dementia found that Caucasians used approximately twice as many antidepressants and anxiolytic agents as African-Americans ${ }^{18}$. The same study did not identify a relationship between the use of psychotropic medications and the severity of the dementia, but it identified an 
inverse relationship between age and the use of antidepressants, which occurred more frequently among young caregivers. The authors suggested that younger caregivers might request more prescriptions for antidepressants from their doctors than older ones. Surprisingly, they noted that $23 \%$ of the caregivers with depression used anxiolytic agents, and only $19 \%$ were treated with antidepressants.

It is important to note that a decrease in social activities can be associated with the use of psychotropic drugs. The loss of friends, leisure activities or work, as well as the complaint of lack of time for oneself, has been related to the use of psychotropic medication by caregivers ${ }^{9}$. More than half of the caregivers in this earlier study thought that they received little or insufficient help from relatives, with respect to the care of the patient. However, the author of the study pointed out that it was not clear whether the perception of inadequate support itself predicted the increased use of psychotropic medication.

An American study composed by a rural population, which involved caregivers of elderly patients with dementia, showed that the participants significantly used more psychotropic medications without medical prescription (to treat insomnia) than those who were not caregivers (43 versus $3 \%)^{23}$. In the present study, members of the CPD Group used more sleeping pills during the time they took care of an elderly patient than members of the CPND Group. Information on which medication was used was difficult to obtain, owing to the fact that the caregivers often did not remember the names of the drugs. However, this reinforced the possible occurrence of insomnia among the CPD Group.

Physicians that assist patients with dementia must be aware of the caregiver's health. Psychological interventions can reduce the psychological morbidity of caregivers ${ }^{24}$. Six or more sessions of psychological behavioural therapy for family caregivers of patients with dementia reduce the symptoms of psychological disease. Group therapy seems to be less effective than individual therapy ${ }^{16}$.

A Dutch study of 984 informal caregivers identified the demands and needs for professional support of caregivers that take care of patients with dementia. There was a difference between the demands of wives and those of sons/daughters: wives needed more emotional support and sons/daughters needed more information about care in the advanced stages of dementia ${ }^{25}$. This type of study needs to be repeated in Brazil. Knowledge of the needs of caregivers can improve their quality of life and that of the patient ${ }^{26}$, in addition to having a significant impact on public health.

The present study has some limitations, which include the fact that information about psychotropic medication was obtained from caregivers' self-reports. Depressive or physical complaints were not analysed, although the self-perception of health was analysed. These results cannot be extended to all caregivers, and more studies are necessary, with appropriate study designs, and in other areas of Brazil.

It is likely that the number of caregivers in Brazil will increase in parallel with the rapid growth of the elderly population. Government strategies to deal with the characteristics and specific demands of this category of workers should be developed. Caregivers are a group that is susceptible to psychological disease and stress. Some authors use the term "Caregivers' syndrome" to categorize the events that are commonly observed in this population ${ }^{27}$.

In summary, we observed that caregivers of patients with dementia took more psychotropic medications than the ones of patients without dementia. This finding might be an indirect sign of caregiver burden. This research showed the need for proper health care and a reduction of psychotropic drug consumption by caregivers of patients with dementia.

\section{References}

1. IBGE - Instituto Brasileiro de Geografia e Estatística. Síntese de indicadores sociais. Uma análise das condições de vida da população brasileira. Rio de Janeiro; 2008.

2. Wannmache L. Demência: evidências contemporâneas sobre a eficácia dos tratamentos. Uso Racional de Medicamentos: Temas Selecionados. Brasília 2005;2:1-6.

3. Ferri CP, Prince M, Brayne C, et al. Global prevalence of dementia: a Delphi consensus study. Lancet 2005;366:2112-2117.

4. Ministério da Saúde. Secretaria de Gestão do Trabalho e da Educação na Saúde. Guia Prático do Cuidador. Brasília, DF; 2008.

5. Llach X, Suriñach NL, MR G. Calidad de vida, tiempo de dedicación y carga percibida por el cuidador principal informal del enfermo de Alzheimer. Atención Primaria 2004;34:170-177.

6. Etters L, Goodall D, Harrison BE. Caregiver burden among dementia patient caregivers: A review of the literature. J Am Acad Nurse Pract 2008;20:423-428.

7. Ferrara M, Langiano E, Di Brango T, De Vito E, Di Cioccio L, Bauco C. Prevalence of stress, anxiety and depression in with Alzheimer caregivers. Health Qual Life Outcomes 2008;6:93.

8. McCurry SM, Gibbons LE, Logsdon RG, Vitiello MV, Teri L. Insomnia in caregivers of persons with dementia: who is at risk and what can be done about it? Sleep Med Clin 2009;4:519-526.

9. Clipp EC, George LK. Psychotropic drug use among caregivers of patients with dementia. J Am Geriatr Soc 1990;38:227-235.

10. Carlini E, Nappo S, Galduróz J, Noto A. Drogas Psicotrópicas: o que são e como agem. Revista IMESC 2001;3:9-35.

11. APA. Diagnostic and statistical manual of mental disorders. 4th edition ed. Washington, DC: American Psychiatric Association; 1994.

12. Moran M, Lynch CA, Walsh C, Coen R, Coakley D, Lawlor BA. Sleep disturbance in mild to moderate Alzheimer's disease. Sleep Med 2005;6:347-352.

13. Hope T, Keene J, Gedling K, Fairburn CG, Jacoby R. Predictors of institutionalization for people with dementia living at home with a carer. Int J Geriatr Psychiatry 1998;13:682-690.

14. Schulz R, O’Brien AT, Bookwala J, Fleissner K. Psychiatric and physical morbidity effects of dementia caregiving: prevalence, correlates, and causes. Gerontologist 1995;35:771-791.

15. Garrido R, Menezes PR. Impact on caregivers of elderly patients with dementia treated at a psychogeriatric service. Rev Saude Publica 2004;38:835-841. 
16. Rosa E, Lussignoli G, Sabbatini F, et al. Needs of caregivers of the patients with dementia. Arch Gerontol Geriatr 2010;51:54-58.

17. Inouye K, Pedrazzani ES, Pavarini SC, Toyoda CY. Perceived quality of life of elderly patients with dementia and family caregivers: evaluation and correlation. Rev Lat Am Enfermagem 2009;17:187-193.

18. Sleath B, Thorpe J, Landerman LR, Doyle M, Clipp E. African-American and white caregivers of older adults with dementia: differences in depressive symptomatology and psychotropic drug use. J Am Geriatr Soc 2005;53:397-404.

19. Rodrigues MA, Facchini LA, Lima MS. Modifications in psychotropic drug use patterns in a Southern Brazilian city. Rev Saude Publica 2006;40:107-114.

20. Draper BM, Poulos CJ, Cole AM, Poulos RG, Ehrlich F. A comparison of caregivers for elderly stroke and dementia victims. J Am Geriatr Soc 1992;40:896-901.

21. Grafstrom M, Fratiglioni L, Sandman PO, Winblad B. Health and social consequences for relatives of demented and non-demented elderly. A population-based study. J Clin Epidemiol 1992;45:861-870.
22. Perodeau G, Lauzon S, Levesque L, Lachance L. Mental health, stress correlates and psychotropic drug use or non-use among aged caregivers to elders with dementia. Aging Ment Health 2001;5:225-234.

23. MortJR, GasparPM,Juffer DI,Kovarna MB.Comparison of psychotropic agent use among rural elderly caregivers and noncaregivers. Ann Pharmacother 1996;30:583-585.

24. Brodaty $H$, Green A, Koschera A. Meta-analysis of psychosocial interventions for caregivers of people with dementia.J Am Geriatr Soc 2003;51:657-664.

25. Peeters JM, Van Beek AP, Meerveld JH, Spreeuwenberg PM, Francke AL. Informal caregivers of persons with dementia, their use of and needs for specific professional support: a survey of the National Dementia Programme. BMC Nurs 2010;9:9.

26. Gaugler JE, Kane RL, Kane RA, Newcomer R. Unmet care needs and key outcomes in dementia. J Am Geriatr Soc 2005;53:2098-2105.

27. Sabater Mateu MP, Lopez Cortacans G. Dementias: impact on the family and prevention of caregivers' syndrome. Rev Enferm 1998;21:20-26. 